\title{
Effectiveness of Embolization of Inferior Mesenteric Artery to Prevent Type II Endoleak Following Endovascular Aneurysm Repair: A Review of the Literature
}

\author{
Makoto Samura, MD, Noriyasu Morikage, MD, Takahiro Mizoguchi, MD, \\ Yuriko Takeuchi, MD, Takashi Nagase, MD, Takasuke Harada, MD, \\ Kotaro Suehiro, MD, and Kimikazu Hamano, MD
}

Type II endoleak is a common complication that develops after endovascular aneurysm repair. Patients with type II endoleak, which has persisted for 6 months, have a significantly higher rate of aneurysmal sac enlargement, reintervention, and rupture. To date, several studies have examined the effectiveness of preoperative embolization of branch vessels for the prevention of type II endoleak. Particularly, the embolization of the large inferior mesenteric artery (IMA) seems to be a precise, safe, and effective method. IMA is a significant risk factor for type II endoleak. However, there is currently no strong evidence to prove which patients would benefit from preventive IMA embolization. In addition, considering the incidence of type II endoleak and the adverse event rate, routine embolization seems to be unreliable and time-consuming. Moreover, previous reports of preoperative IMA embolization were retrospective. Thus, prospective and randomized studies are necessary so that the usefulness of IMA embolization can be proved and the potential benefits can be assessed. To establish preventive IMA embolization as one of the effective therapeutic strategies to prevent type II endoleak and to maximize its therapeutic effect, we should provide a wide range of therapeutic strategies to suit the state of the patient.

Division of Vascular Surgery, Department of Surgery and Clinical Science, Yamaguchi University Graduate School of Medicine, Ube, Yamaguchi, Japan

Received: June 1, 2018; Accepted: July 11, 2018

Corresponding author: Noriyasu Morikage, MD. Division of Vascular Surgery, Department of Surgery and Clinical Science, Yamaguchi University Graduate School of Medicine, 1-1-1 Minami-Kogushi, Ube, Yamaguchi 755-8505, Japan

Tel: +81-836-22-2261, Fax: +81-836-38-2210

E-mail: morikage@yamaguchi-u.ac.jp

(cc) BY-NC-SA (C2018 The Editorial Committee of Annals of Vascular Diseases. This article is distributed under the terms of the Creative Commons Attribution License, which permits use, distribution, and reproduction in any medium, provided the credit of the original work, a link to the license, and indication of any change are properly given, and the original work is not used for commercial purposes. Remixed or transformed contributions must be distributed under the same license as the original.
Keywords: EVAR, type II endoleak, IMA embolization

\section{Introduction}

In recent years, endovascular aneurysm repair (EVAR) has become a promising therapy for abdominal aortic aneurysms (AAAs). The aim of this treatment is the removal of systemic pressure within the aneurysmal sac by the placement of intraluminal stent grafts, and the prevention of aneurysmal sac enlargement and rupture. EVAR is an endoluminal procedure; thus, it is less invasive. Compared to open repair, it has been associated with a reduced early mortality and lower complication rates., ${ }^{1,2)}$ However, incomplete exclusion of the aneurysmal sac from the circulation, called an endoleak, is the most common complication that develops after EVAR, ${ }^{1)}$ and the reintervention rate in long-term outcomes has been reported to be significantly higher than in open repair. ${ }^{3,4)}$

Endoleaks can be classified into five types, types I-V. Type I endoleak results from inadequate graft sealing at the proximal (Ia) or distal segments (Ib) of the aneurysmal sealing site. The poor sealing allows systemic blood into the aneurysmal sac along the side of the graft, and creates systemic pressure within the aneurysmal sac. Type II endoleak results from retrograde perfusion into the aneurysmal sac from the aneurysmal side branches, such as the inferior mesenteric artery (IMA) and the lumbar arteries (LAs). This problematic complication is the most common type of endoleak. ${ }^{5)}$ Type III endoleak results from junctional separation between the components of the grafts (IIIa) or from a fracture of the graft, a hole, or a defect in the graft fabric (IIIb). Similar to type I endoleak, there is a direct communication between the systemic circulation and the aneurysmal sac through the defect or misalignment of graft components in type III endoleak. Type IV endoleak results from blood leakage across the graft due to the porosity of certain graft materials. This endoleak type is self-limited, and resolves spontaneously as the 
perioperative patient's anticoagulation function returns to baseline. Type $\mathrm{V}$ endoleak, also called endotension, is not a true leak, but is the continued expansion of the aneurysmal sac without evidence of any detected endoleak. $\left.{ }^{6}\right)$ Type I and III endoleaks are high-pressure leaks for outside the graft. They cause systemic pressure to build within the aneurysmal sac. Additionally, they are considered treatment failures, for which immediate reintervention is required to prevent sac enlargement and rupture. ${ }^{7)}$ Type IV endoleak causes low-pressure leakage into the aneurysmal sac, but is often spontaneously resolved. Thus, usually, no additional procedures are needed. Type $\mathrm{V}$ endoleak is poorly understood. Moreover, due to the limitation of imaging techniques, there is a possibility not to detect the flow into the aneurysmal sac. Therefore, there is no consensus on how to manage this type of endoleak. ${ }^{8)}$

Although the cause of type II endoleak is known its management remains controversial. ${ }^{9)}$ Aortic side branches, including IMA and LAs, are normally sacrificed during open repair, but during EVAR, these branches are not embolized. This leads to retrograde low-pressure perfusion of the aneurysm sac. In $50 \%-80 \%$ of cases type II endoleak is spontaneously resolved within the first 6 months after EVAR; therefore, treatment during this period is usually unnecessary. ${ }^{10,11)}$ However, patients with type II endoleak, which has persisted for 6 months, have a significantly higher rate of sac enlargement, reintervention, conversion to open repair, and rupture. ${ }^{12)}$ Therefore, type II endoleak persisting for 6 months is defined as a problematic and persistent type II endoleak. Based on this, we will refer to type II endoleak as "persistent type II endoleak."

Many attempts have been made to manage type II endoleak after EVAR to avoid adverse events. However, because of the presence of collateral networks of side branches, sac enlargement due to type II endoleak could not be controlled via reinterventions such as transarterial retrograde embolization. ${ }^{13,14)}$ Several studies have examined the effectiveness of preoperative, not postoperative, embolization of side branches to prevent type II endoleak. ${ }^{15-25)}$ Moreover, reports suggest that sac embolization during EVAR reduced type II endoleak. ${ }^{25-27)}$

Therefore, it is important to prevent, rather than to treat, the adverse events that could arise from type II endoleak after EVAR.

Here, we mainly review the challenges and limitations of type II endoleak management after EVAR raised in previous studies. We also discuss the potential strategies to prevent type II endoleak.

\section{The Risk Factors of Type II Endoleaks}

In recent years, the factors associated with type II endoleak development have gradually become clear. These in- clude anatomical and patient background-related factors.

According to some reports regarding the representative anatomical risk factors, IMA and LAs patency are independent risk factors for type II endoleak. ${ }^{28-30)}$ According to other reports, the diameters of these vessels were also significant risk factors for type II endoleak. ${ }^{5,31)}$ It is understandable that when there are more patent side branches of larger sizes, there may be a greater chance of developing type II endoleak. In our previous study, the most affected anatomical risk factor for type II endoleak was the patency of IMA (odds ratio, 4.13; $\mathrm{P}=.004$ ). ${ }^{32}$ ) In the study, type II endoleak was detected in $31.8 \%$ of patients with patent IMA. However, type II endoleak was detected in only $9.4 \%$ of patients with occluded IMA $(\mathrm{P}<.001)$. In a further examination, we discovered that in addition to IMA patency, IMA $\geqq 3.0 \mathrm{~mm}$ (odds ratio, $4.09 ; \mathrm{P}=.011$ ) and LAs $\geqq 2.0 \mathrm{~mm}$ (odds ratio, 3.16; $\mathrm{P}=.043$ ) were also independent risk factors of type II endoleak. Another significant risk factor of type II endoleak in patients with patent IMA was aortoiliac-type aneurysms extending to the iliac arteries (odds ratio, 6.36; $\mathrm{P}=.026$ ). However, we could not determine why an aortoiliac-type aneurysm was more predisposing to type II endoleak than was an aortictype aneurysm. A possible explanation for the increased risk of type II endoleak among patients with an aortoiliactype aneurysm is that this aneurysm may be in a worse atherosclerotic state than the aortic-type aneurysm. Moreover, patients with aortoiliac-type aneurysm are usually older patients or they may have a large sac volume ${ }^{33,34)}$ and may be at risk of a patent IMA or LAs.

Concerning patient background-related risk factors, some reports suggest that a non-smoking lifestyle is associated with a high risk of type II endoleak. ${ }^{35-37)}$ In general, through a pathological change such as high platelet aggregation, endothelial dysfunction, and arterial wall thickening, habitual smoking induces atherosclerosis. Atherosclerosis of branch arteries derived from the aneurysmal sac, such as IMA and LAs, impair retrograde perfusion into the aneurysmal sac. Moreover, smoking induces a coagulated state, ${ }^{38)}$ and this might lead to thrombosis of the aneurysmal lumen and could reduce the type II endoleak. Another background-related risk factor is old age. ${ }^{33,39,40)}$ The reason for this is unclear. As mentioned earlier, older patients have a long history of AAAs, large sac volume, and a worse atherosclerotic state. This may be a reason why aging is a risk factor for type II endoleak.

Moreover, Guo et al. and Lalys et al. reported metaanalysis data on the risk factors for type II endoleak including the abovementioned factors. ${ }^{41,42}$ ) Since these reports had similar results, it may be considered that a consensus on the risk factors for type II endoleak was almost obtained. 


\section{The Preventive Methods of Type II Endole- aks}

IMA patency is a strong risk factor for type II endoleak. Thus, it is considered that preoperative IMA embolization may be effective in preventing type II endoleak. Preoperative embolization of IMA significantly reduced type II endoleak in high-risk patients (IMA patency and diameter $>2.5 \mathrm{~mm})$ in our small case series $(0 \% ; 0 / 15) .{ }^{32)}$ Currently, several studies have demonstrated that preoperative IMA embolization could prevent type II endoleak (Table 1). In addition, Manunga et al. reported meta-analysis data to show the effectiveness of preoperative IMA embolization. ${ }^{43}$ This data showed that preoperative IMA embolization protected against type II endoleak in the embolization group compared to the non-embolization group (odds ratio, $0.31 ; \mathrm{P}<.001$ ), and it also significantly reduced the secondary intervention ratio (odds ratio, 0.12 ; $\mathrm{P}<.001)$.

Contrarily, the embolization of LAs in addition to IMA embolization is also considered an effective method. Some studies reported the effectiveness of the embolization of both IMA and LAs (especially in LAs with a diameter of $\geqq 2 \mathrm{~mm}$ ), and indicated that their embolization was more useful in preventing type II endoleak than IMA embolization alone was (Table 1). However, LAs embo- lization could not be achieved in all attempts. Bonvini et al. reported the technical success rates of preoperative embolization to be considerably higher for IMA than for LAs $(100 \%$ versus $65 \%) .{ }^{21)}$ In general, LAs are small and tortuous. Moreover, LAs are vertical branches that course from an aneurysm, and LAs orifice tangentially originates from the procedural direction. Therefore, cannulation of the catheter and embolization of all targeted LAs seem to be more difficult than those of IMA.

The complication rate was extremely low regarding preoperative branch vessel embolization (Table 1). However, Ward et al. described a patient with a history of colonic resection who had serious mesenteric ischemia, which resulted in mortality after preventive IMA embolization prior to EVAR. ${ }^{18)}$ In IMA embolization, the risk of mesenteric ischemia is minimized by precise proximal embolization. The embolization proximal to the left colic artery allows the collateral blood flow to the IMA branches to remain intact, including the arcade of Riolan. However, care should be taken to avoid mesenteric ischemia in patients who have a history of a procedure that interrupted the colic arteries.

Fluoroscopy time and the use of a contrast agent could be increased in difficult settings such as in LAs embolization. In patients with high morbidity such as patients with renal dysfunction, the potential burden on them should be

Table 1 Preventive vessel embolization

\begin{tabular}{|c|c|c|c|c|c|c|c|c|c|c|}
\hline Author & Year & $\begin{array}{c}\text { Target } \\
\text { vessels }\end{array}$ & Indication & $\begin{array}{l}\text { Embolus } \\
\text { source }\end{array}$ & $\begin{array}{l}\text { Technical } \\
\text { success }\end{array}$ & $\begin{array}{c}\text { Study } \\
\text { population }\end{array}$ & Outcome & Complication & Follow-up & Reference \\
\hline Axelrod et al. & 2004 & IMA & patent IMA & coil & $94 \%$ & 30 & $5 / 30 ; 17 \%$ & none & $\begin{array}{c}\text { not- } \\
\text { determined }\end{array}$ & [15] \\
\hline Muthu et al. & 2007 & IMA & patent IMA & $\begin{array}{l}\text { coil, } \\
\text { thrombin }\end{array}$ & $41 \%$ & 69 & $10 / 69 ; 14 \%$ & none & $12 \mathrm{mo}$ & [16] \\
\hline Nevala et al. & 2010 & IMA & patent IMA & coil & $100 \%$ & 40 & $10 / 40 ; 25 \%$ & none & $3.4 \mathrm{yr}$ & [17] \\
\hline Ward et al. & 2013 & IMA & patent IMA & coil & $100 \%$ & 108 & $\begin{array}{c}37 / 108 \\
34.3 \%\end{array}$ & $\begin{array}{l}\text { 1, mesenteric } \\
\text { ischemia }\end{array}$ & $985 d$ & [18] \\
\hline Müller-Wille et al. & 2014 & IMA & $\mathrm{IMA} \geqq 3 \mathrm{~mm}$ & plug & $100 \%$ & 31 & $6 / 31 ; 19.4 \%$ & none & $\begin{array}{c}\text { not- } \\
\text { determined }\end{array}$ & [19] \\
\hline Parry et al. & 2002 & $\begin{array}{l}\text { IMA, } \\
\text { LAs }\end{array}$ & $\begin{array}{c}\text { LAs }>1.5 \mathrm{~mm} \text {, } \\
\text { patent IMA }\end{array}$ & coil & $\begin{array}{c}81 \%(\text { IMA) } \\
62 \%(\mathrm{LA})\end{array}$ & 14 & $0 / 14 ; 0 \%$ & none & $24 \mathrm{mo}$ & [20] \\
\hline Bonvini et al. & 2003 & $\begin{array}{l}\text { IMA, } \\
\text { LAs }\end{array}$ & $\begin{array}{l}\text { LAs }>2 \mathrm{~mm} \text {, } \\
\text { patent IMA }\end{array}$ & coil & $\begin{array}{c}100 \% \text { (IMA) } \\
65 \%(\mathrm{LA})\end{array}$ & 23 & $1 / 23 ; 4.5 \%$ & none & $17 \mathrm{mo}$ & [21] \\
\hline Alerci et al. & 2013 & $\begin{array}{l}\text { IMA, } \\
\text { LAs }\end{array}$ & $\begin{array}{l}\text { vessels } \\
\text { diameter } \\
\geqq 2 \mathrm{~mm}\end{array}$ & coil & $91 \%$ & 56 & $1 / 56 ; 3.6 \%$ & none & $60.5 \mathrm{mo}$ & [22] \\
\hline Chikazawa et al. & 2013 & $\begin{array}{l}\text { IMA, } \\
\text { others }\end{array}$ & $\begin{array}{c}\text { LAs } \geqq 2 \mathrm{~mm} \text {, } \\
\text { patent IMA }\end{array}$ & coil & $\begin{array}{c}100 \%(\mathrm{IMA}) \\
79.8 \%(\mathrm{LA})\end{array}$ & 21 & $\begin{array}{c}\text { not-determined/ } \\
21 ; 24 \%\end{array}$ & none & $\begin{array}{c}\text { not- } \\
\text { determined }\end{array}$ & [23] \\
\hline Burbelko et al. & 2014 & $\begin{array}{l}\text { IMA, } \\
\text { others }\end{array}$ & $\begin{array}{l}\text { vessels } \\
\text { diameter } \\
>2.5 \mathrm{~mm}\end{array}$ & plug, coil & $92 \%$ & 37 & $0 / 37 ; 0 \%$ & none & $30.1 \mathrm{mo}$ & [24] \\
\hline Aoki et al. & 2017 & $\begin{array}{l}\text { IMA, } \\
\text { LAs }\end{array}$ & $\begin{array}{l}\text { LAs } \geqq 2 \mathrm{~mm} \text {, } \\
\text { patent IMA }\end{array}$ & coil & $\begin{array}{c}93.8 \% \text { (IMA), } \\
64.4 \% \text { (LA) }\end{array}$ & 24 & $1 / 24 ; 4.2 \%$ & none & $\begin{array}{c}\text { not- } \\
\text { determined }\end{array}$ & [25] \\
\hline
\end{tabular}

IMA: inferior mesenteric artery; LA: lumbar artery; d: days; mo: month; yr: year 
considered.

Moreover, the promotion of thrombus formation inside the aneurysmal sac is considered another possible method of preventing type II endoleak. Aoki et al. reported that coil, thrombin, gelform, and fibrin glue were useful in promoting aneurysmal sac thrombosis. ${ }^{25)}$ The injection of these materials into the aneurysmal sac would be to promote thrombosis inside the aneurysm, leading to branch vessel occlusion and the prevention of type II endoleak. Particularly, these liquid materials could also seal off the orifice of LAs, which is considered difficult to embolize according to gravity. However, injecting these liquids into the aneurysmal sac has resulted in several adverse events, including colonic ischemia and paraplegia. ${ }^{44)}$ These procedures might be useful if embolization of targeted branch vessels was difficult and unsuccessful. However, among the above-listed materials, it is still controversial which materials are optimal to promote aneurysmal sac thrombosis and branch vessel occlusion, and the procedure of which is most safely performed. Thus, further studies are needed to determine the optimal materials.

\section{The Source of IMA Embolization}

The classical source of branch vessel embolization is using stainless steel or platinum coils (Table 1). However, this method has some disadvantages. First, it is expensive because of the use of an additional microcatheter and guidewire, and because several coils are required to achieve occlusion. Another disadvantage is that because of metal halation due to the coils, poor-quality computed tomography (CT) images are obtained during follow-up evaluation, and this leads to difficulty in examining the endoleak in detail.

In recent years, Müller-Wille et al. and Burbelko et al. demonstrated IMA embolization to prevent type II endoleak using a vascular plug, another type of embolization device, and reported good results. ${ }^{19,24)}$ We have also used vascular plugs for IMA embolization and reported our unique technique. ${ }^{45)}$ Our technique is a specific approach that does not involve the use of additional devices such as microcatheters and guidewires. Therefore, the additional cost of IMA embolization using this technique during EVAR is only the price of the vascular plug. Moreover, the procedure was performed during EVAR with only femoral access and minimal additional time (the median procedure time was around $11.6 \mathrm{~min}$ ). The success rate of our technique was $90.9 \%$, and there were no adverse events. Further, the vascular plug does not cause metal halation, and precise follow-up evaluation using CT can be performed. Therefore, the vascular plug could be one of the useful sources of IMA embolization.

\section{The Target Patients for the Prevention Methods}

If IMA embolization could be performed simply, safely, and effectively, it could be one of the useful strategies to prevent type II endoleak.

However, an important point to note here is the selection of patients for the preventive procedure. There is currently no strong evidence showing which patients would benefit from a preventive intervention to avoid type II endoleak. ${ }^{46)}$ Target and routine embolization of side branches or the aneurysmal sac seem unreliable, time-consuming, and involve high-risk considering the incidence of type II endoleak and the adverse event rate. To effectively prevent type II endoleak, procedures should be precise and safe, and according to the anatomical risk factors mentioned above, such as IMA and LAs diameter, they should be performed for selected patients.

Based on our previous study, we defined patients with the following characteristics as being at high risk of developing type II endoleak (patients without these characteristics were considered at low risk): (1) IMA patency, $\geqq 3 \mathrm{~mm}$ in diameter, (2) IMA patency and at least one LA with a diameter of $\geqq 2 \mathrm{~mm}$, and (3) IMA patency and an aortoiliac-type aneurysm. Based on these criteria, we identified 98/196 (50.0\%) patients at high risk and 98/196 (50.0\%) patients at low risk of developing type II endoleak. By applying these criteria, type II endoleak was detected in $37 / 98(31.8 \%)$ of high-risk patients and 11/98 (11.2\%) of low-risk patients $(\mathrm{P}<.001) .{ }^{32)}$ Thus, about $50 \%$ of patients planned for EVAR could be candidates for preventive procedures. Similar to our definition, Piazza et al. also applied the following factors based on the anatomical criteria for preventive aneurysmal sac embolization in patient selection: (1) IMA patency, with a luminal diameter at origin of $\geqq 3 \mathrm{~mm},(2)$ patency of at least three pairs of LAs or two pairs of LAs and a sacral artery or accessory renal artery, or any diameter (including $<3 \mathrm{~mm}$ ) of IMA patency. ${ }^{26)}$ Based on their criteria, 107/126 (84.9\%) patients were at high risk and 19/126 (15.1\%) patients were at low risk of developing type II endoleak. The proportion of candidates who are eligible for preventive procedures is dependent on the definition of anatomical risk factors.

However, in any case, many patients should be candidates for preventive intervention. Therefore, the therapeutic indication for preventive intervention should be decided on considering the patient's characteristics such as age, comorbidities, and aneurysmal size.

\section{Prospective and Randomized Study to Con- firm the Effectiveness of IMA Embolization}

The limitation of previous studies on preventive IMA em- 
bolization was that they were all retrospective. Prospective and randomized studies are needed to prove the usefulness of IMA embolization and to assess the potential benefits.

In September 2014, we started a prospective randomized multi-center study to evaluate the effectiveness of preventive IMA embolization. The study protocol was approved by the ethics committee of our institution and the University Hospital Medical Information Network Clinical Trials Registry in Japan (UMIN000022147). Currently, patient registration has been concluded. We would publish the results soon.

\section{Conclusion}

The efficacy and safety of strategies to prevent type II endoleak have been demonstrated in several retrospective clinical trials. However, the therapeutic outcomes are still controversial, and further studies, such as our ongoing prospective randomized study, on the management of type II endoleak are needed to determine the clinical applications. We hypothesize that preoperative IMA embolization is one of the options to reduce type II endoleak. In addition, appropriate selection of target patients based on the anatomical risk factors might bring the usefulness of this approach to full play in clinical settings.

\section{Acknowledgments}

We thank Dr. Yuya Tanaka and Dr. Osamu Yamashita for their helpful discussion and comments.

\section{Funding Sources}

This research did not receive any specific grant from funding agencies in the public, commercial, or not-for-profit sectors.

\section{Disclosure Statement}

All authors have no conflict of interest.

\section{Author Contributions}

Study conception: NM

Data collection: MS, TM, YT, TN, TH, KS

Analysis: MS

Investigation: MS

Writing: MS

Funding acquisition: NM, KH

Critical review and revision: all authors

Final approval of the article: all authors

Accountability for all aspects of the work: all authors

\section{References}

1) Greenhalgh RM, Brown LC, Kwong GP, et al. Comparison of endovascular aneurysm repair with open repair in patients with abdominal aortic aneurysm (EVAR trial 1), 30-day operative mortality results: randomised controlled trial. Lancet 2004; 364: 843-8.

2) EVAR trial participants. Endovascular aneurysm repair versus open repair in patients with abdominal aortic aneurysm (EVAR trial 1): randomised controlled trial. Lancet 2005; 365: 2179-86.

3) Lederle FA, Freischlag JA, Kyriakides TC, et al. Outcomes following endovascular vs open repair of abdominal aortic aneurysm: a randomized trial. JAMA 2009; 302: 1535-42.

4) The United Kingdom EVAR Trial Investigators. Endovascular versus open repair of abdominal aortic aneurysm. N Engl J Med 2010; 362: 1863-71.

5) Marchiori A, von Ristow A, Guimaraes M, et al. Predictive factors for the development of type II endoleaks. J Endovasc Ther 2011; 18: 299-305.

6) Rosen RJ, Green RM. Endoleak management following endovascular aneurysm repair. J Vasc Interv Radiol 2008; 19 Suppl: S37-43.

7) White SB, Stavropoulos SW. Management of endoleaks following endovascular aneurysm repair. Semin Intervent Radiol 2009; 26: 33-8.

8) Synowiec T, Warot M, Burchardt P, et al. All dangerous types of endoleaks after endovascular aneurysm repair in a single patient. Wideochir Inne Tech Malo Inwazyjne 2015; 10: 290-4.

9) Lawrence-Brown MM, Sun Z, Semmens JB, et al. Type II endoleaks: when is intervention indicated and what is the index of suspicion for types I or III? J Endovasc Ther 2009; 16 Suppl 1: I106-18.

10) Sidloff DA, Gokani V, Stather PW, et al. Type II endoleak: conservative management is a safe strategy. Eur J Vasc Endovasc Surg 2014; 48: 391-9.

11) Biancari F, Mäkelä J, Juvonen T, et al. Is inferior mesenteric artery embolization indicated prior to endovascular repair of abdominal aortic aneurysm? Eur J Vasc Endovasc Surg 2015; 50: 671-4.

12) Jones JE, Atkins MD, Brewster DC, et al. Persistent type 2 endoleak after endovascular repair of abdominal aortic aneurysm is associated with adverse late outcomes. J Vasc Surg 2007; 46: 1-8.

13) Solis MM, Ayerdi J, Babcock GA, et al. Mechanism of failure in the treatment of type II endoleak with percutaneous coil embolization. J Vasc Surg 2002; 36: 485-91.

14) Gallagher KA, Ravin RA, Meltzer AJ, et al. Midterm outcomes after treatment of type II endoleaks associated with aneurysm sac expansion. J Endovasc Ther 2012; 19: 182-92.

15) Axelrod DJ, Lookstein RA, Guller J, et al. Inferior mesenteric artery embolization before endovascular aneurysm repair: technique and initial results. J Vasc Interv Radiol 2004; 15 : 1263-7.

16) Muthu C, Maani J, Plank LD, et al. Strategies to reduce the rate of type II endoleaks: routine intraoperative embolization of the inferior mesenteric artery and thrombin injection into the aneurysm sac. J Endovasc Ther 2007; 14: 661-8.

17) Nevala T, Biancari F, Manninen $H$, et al. Inferior mesen- 
teric artery embolization before endovascular repair of an abdominal aortic aneurysm: effect on type II endoleak and aneurysm shrinkage. J Vasc Interv Radiol 2010; 21: 181-5.

18) Ward TJ, Cohen S, Fischman AM, et al. Preoperative inferior mesenteric artery embolization before endovascular aneurysm repair: decreased incidence of type II endoleak and aneurysm sac enlargement with 24-month follow-up. J Vasc Interv Radiol 2013; 24: 49-55.

19) Müller-Wille R, Uller W, Gössmann H, et al. Inferior mesenteric artery embolization before endovascular aortic aneurysm repair using amplatzer vascular plug type 4 . Cardiovasc Intervent Radiol 2014; 37: 928-34.

20) Parry DJ, Kessel DO, Robertson I, et al. Type II endoleaks: predictable, preventable, and sometimes treatable? J Vasc Surg 2002; 36: 105-10.

21) Bonvini R, Alerci M, Antonucci F, et al. Preoperative embolization of collateral side branches: a valid means to reduce type II endoleaks after endovascular AAA repair. J Endovasc Ther 2003; 10: 227-32.

22) Alerci M, Giamboni A, Wyttenbach R, et al. Endovascular abdominal aneurysm repair and impact of systematic preoperative embolization of collateral arteries: endoleak analysis and long-term follow-up. J Endovasc Ther 2013; 20: 663-71.

23) Chikazawa G, Yoshitaka H, Hiraoka A, et al. Preoperative coil embolization to aortic branched vessels for prevention of aneurysmal sac enlargement following EVAR: early clinical result. Ann Vasc Dis 2013; 6: 175-9.

24) Burbelko M, Kalinowski M, Heverhagen JT, et al. Prevention of type II endoleak using the AMPLATZER vascular plug before endovascular aneurysm repair. Eur J Vasc Endovasc Surg 2014; 47: 28-36.

25) Aoki A, Maruta K, Hosaka N, et al. Evaluation and coil embolization of the aortic side branches for prevention of type II endoleak after endovascular repair of abdominal aortic aneurysm. Ann Vasc Dis 2017; 10: 351-8.

26) Piazza M, Squizzato F, Zavatta M, et al. Outcomes of endovascular aneurysm repair with contemporary volume-dependent sac embolization in patients at risk for type II endoleak. J Vasc Surg 2016; 63: 32-8.

27) Mascoli C, Freyrie A, Gargiulo M, et al. Selective intraprocedural AAA sac embolization during EVAR reduces the rate of type II endoleak. Eur J Vasc Endovasc Surg 2016; 51: 632-9.

28) Velazquez OC, Baum RA, Carpenter JP, et al. Relationship between preoperative patency of the inferior mesenteric artery and subsequent occurrence of type II endoleak in patients undergoing endovascular repair of abdominal aortic aneurysms. J Vasc Surg 2000; 32: 777-88.

29) Ward TJ, Cohen S, Patel RS, et al. Anatomic risk factors for type-2 endoleak following EVAR: a retrospective review of preoperative CT angiography in 326 patients. Cardiovasc Intervent Radiol 2014; 37: 324-8.

30) Timaran CH, Ohki T, Rhee SJ, et al. Predicting aneurysm enlargement in patients with persistent type II endoleaks. J Vasc Surg 2004; 39: 1157-62.

31) Otsu M, Ishizaka T, Watanabe $M$, et al. Analysis of ana- tomical risk factors for persistent type II endoleaks following endovascular abdominal aortic aneurysm repair using CT angiography. Surg Today 2016; 46: 48-55.

32) Samura M, Morikage N, Mizoguchi T, et al. Identification of anatomical risk factors for type II endoleak to guide selective inferior mesenteric artery embolization. Ann Vasc Surg 2017; Dec 22. [Epub ahead of print].

33) Abularrage CJ, Crawford RS, Conrad MF, et al. Preoperative variables predict persistent type 2 endoleak after endovascular aneurysm repair. J Vasc Surg 2010; 52: 19-24.

34) El Batti S, Cochennec F, Roudot-Thoraval F, et al. Type II endoleaks after endovascular repair of abdominal aortic aneurysm are not always a benign condition. J Vasc Surg 2013; 57: 1291-7.

35) Lottman PE, van Marrewijk CJ, Fransen GA, et al. Impact of smoking on endovascular abdominal aortic aneurysm surgery outcome. Eur J Vasc Endovasc Surg 2004; 27: 512-8.

36) Koole D, Moll FL, Buth J, et al. The influence of smoking on endovascular abdominal aortic aneurysm repair. J Vasc Surg 2012; 55: 1581-6.

37) Fujimura N, Obara H, Matsubara K, et al. Characteristics and risk factors for type 2 endoleak in an East Asian population from a Japanese multicenter database. Circ J 2016; 80: 118-23.

38) Yarnell JWG, Sweetnam PM, Rumley A, et al. Lifestyle factors and coagulation activation markers. The Carphilly study. Blood Coagul Fibrinolysis 2001; 12: 721-8.

39) van Marrewijk CJ, Fransen G, Laheij RJF, et al. Is a type II endoleak after EVAR a harbinger of risk? Causes and outcome of open conversion and aneurysm rupture during follow-up. Eur J Vasc Endovasc Surg 2004; 27: 128-37.

40) Lo RC, Buck DB, Herrmann J, et al. Risk factors and consequences of persistent type II endoleaks. J Vasc Surg 2016; 63: 895-901.

41) Guo Q, Du X, Zhao J, et al. Prevalence and risk factors of type II endoleaks after endovascular aneurysm repair: a meta-analysis. PLoS ONE 2017; 12: e0170600.

42) Lalys F, Durrmann V, Duménil A, et al. Systematic review and meta-analysis of preoperative risk factors of type II endoleaks after endovascular aneurysm repair. Ann Vasc Surg 2017; 41: 284-93.

43) Manunga JM, Cragg A, Garberich R, et al. Preoperative inferior mesenteric artery embolization: a valid method to reduce the rate of type II endoleak after EVAR? Ann Vasc Surg 2017; Dec 22. [Epub ahead of print]

44) Buckenham T, McKewen M, Laing A, et al. Cyanoacrylate embolization of endoleaks after abdominal aortic aneurysm repair. ANZ J Surg 2009; 79: 841-3.

45) Morikage N, Samura M, Takeuchi Y, et al. Innovative procedure for inferior mesenteric artery embolization using the amplatzer vascular plug 4 during endovascular aneurysm repair. Ann Vasc Surg 2017; 44: 431-8.

46) Gould DA, McWilliams R, Edwards RD, et al. Aortic side branch embolization before endovascular aneurysm repair: incidence of type II endoleak. J Vasc Interv Radiol 2001; 12: 337-41. 